\title{
Facing paradoxical identities: How Indonesian organic food community unify consumers and environmentalist identities
}

\author{
Estu Putri Wilujeng ${ }^{1^{*}}$ \\ ${ }^{1}$ Department of Sociology, Universitas Indonesia, Indonesia \\ *Corresponding author \\ E-mail address: estuputri@ui.ac.id \\ DOI: https://doi.org/10.21107/sml.v4i1.10002
}

\begin{tabular}{|c|c|}
\hline Article Info & A BStract \\
\hline $\begin{array}{l}\text { Keywords: } \\
\text { organic food } \\
\text { communities } \\
\text { identity } \\
\text { environmental } \\
\text { movement } \\
\text { material culture } \\
\text { cultural sociology }\end{array}$ & $\begin{array}{l}\text { This article explored how the Indonesian organic food community builds its } \\
\text { identity as both consumers and environmentalists, which is often thought } \\
\text { to be a paradox. Some researchers argue that combining consumption and } \\
\text { environmental preservation under green consumption is a challenge and an } \\
\text { oxymoron. Nevertheless, the organic food community is still able to build their } \\
\text { identities. The author argued that organic communities have transformed } \\
\text { into space to empower and shape those identities using conventional and } \\
\text { new media as part of green political consumerism. To understand this issue, } \\
\text { the author used qualitative research by collecting the communities' official } \\
\text { documents, webpage, and social media accounts' posts. The author also } \\
\text { interviewed the founders of two communities, Komunitas Organik Indonesia } \\
\text { (KOI/ Indonesian Organic Community) and Lingkar Organik (LO/ Organic } \\
\text { Circle), a KOI member. The author did participatory observation in one of } \\
\text { KOI's WhatsApp Groups for their members. Then, the author triangulated } \\
\text { the data and analyzed it. The results revealed that communities maintain and } \\
\text { transform their green value into identities and real action by conditioning } \\
\text { their members with community structures, activities, and access to organic } \\
\text { food either through online or offline services. Therefore, having both } \\
\text { identities is not a paradox. }\end{array}$ \\
\hline
\end{tabular}

Citation suggestion:

Wilujeng, E. P. (2021). Facing paradoxical identities: How Indonesian organic food community unify consumers and environmentalist identities. Simulacra, 4(1), 71-86. https://doi.org/10.21107/sml.v4i1.10002

Received 19 February 2021; Received in revised form 27 March 2021; Accepted 4 April 2021; Published online 25 June 2021. 


\section{Introduction}

Food is a culture because it is constructed and managed by a human (Montanari, 2017). Food also can reflect the condition of an individual, a social group, or society because it contains value and symbols. Those values and symbols determine the standard of delicacy and menu, the production and distribution process, and the manner in daily life (Back et al., 2012). Those values and symbols also exist in organic food. Organic food consumers have their delicacy standard, production cycle, and the manner in daily life.

Ma, Zhao, \& Ren (2010) argue that the food production cycle starts with the initial process and ends with the disposal process. It consists of food preparation, processing, packaging, distribution or transportation, use, and disposal. Based on this production cycle, organic foods produce only two-thirds of carbon dioxide levels than the agricultural industry per hectare. Consuming organic groceries, processed food and ready-toeat food in the local production places can reduce carbon emissions because of the lower distribution energy than national or global production.

On the other side, some researchers argue that green consumerism, which includes organic food, is a problematic concept because it is often considered oxymoronic (Hardner \& Rice, 2002; Monteith \& Giesbert, 2016; Peattie, 2010). Peattie (2010) explains that green consumption issues lay in the contradiction between green concepts and consumption. The green concept refers to natural resources conservation, while consumption is generally a destructive activity that depletes resources. Hardner \& Rice (2002) point out that buying green products cannot save the diversity of living things in nature. Also, Akenji (2014) argues that the focus on green consumers blurs the structural and systemic causes of environmental issues. Moreover, Harrison (2006) reveals that green product purchasing was reinvested outside the green product lifecycle. Buttel (2003) explains that there is a debate among environmental sociologists, some of them find that the influence of individuals in maintaining and changing the environment by reducing consumption or purchasing green products such as organic or recycled foods is ineffective, yet the other environmental sociologists strongly argue that it is essential to examine individual consumption seriously.

Green consumerism is a form of consumption-oriented for sustainable development. It is defined as value and activity that positively impacts the environment and has an essential role in reducing greenhouse gas emissions per capita (Sachdeva, Jordan, and Mazar, 2015). Some familiar green consumption attitudes are recycling, carrying our shopping bags, purchasing, and consuming environmentally friendly products (Tan, Johnstone, and Yang, 2016).

Green consumerism is also political. Influencing the public to use green products, understand their value, and integrate it into the lifestyle, also provide a better production, distribution, and consumption system is a part of green political consumerism. Individuals or communities can get involved in the green political movement by sharing green product value with the public, yet it is often emphasized on an individual scale. As Boström, M., \& Klintman (2017) state, green campaigns inform and attract the freedom of individual will and morality to have ethical and environmental concerns as an environmentally responsible actor as part of their self-image construction. Nevertheless, the morality and responsibility to have an environmental concern can happen at the community level, and the individual level can be transformed into the community level. 
The consumption and environmental preservation cannot be unified, yet based on green consumerism, which is political, those values still can be unified. This study argued that organic food consumption and environmental preservation could be unified and effective to reduce the environmental issues if the consumers commune as a community movement. Organic food communities can become spaces to share organic food value, knowledge, material to build multi-identities to their members, healthy consumers, and environmental preserver. The building process happens in physical and digital spaces. In those spaces, they interact based on the community structure to empower their members, yet the members also can ignore the community governance in the identities building process. It depends on the community and the members themselves as a dynamic process includes the challenge both in physical and digital space.

The organic food communities studied were the Komunitas Organik Indonesia (KOI/ Indonesian Organic Community) and Lingkar Organik (LO/ Organic Circle, a KOI member. KOI is located in Jakarta, while LO is located in Yogyakarta. These communities have been concerned about organic products for more than a decade. They have combined physical and digital spaces to share the value and products with their members. KOI uses new media to socialize the benefits of organic products and interact with its members to exchange information and products (Atmadi, 2013). They utilize Facebook, Instagram, Twitter, an official webpage, a special event webpage, and a WhatsApp group chat called Komunitas Selaras Alam (KSA/ In Harmony with Nature Community). KOI also has annual events and special occasions in physical and digital spaces. Other than that, KOI also developed another program, such as Balai Belajar Bali (BBB or Bali Learning Hall) in Tabanan, Bali.
Those communities were studied to answer the main questions: how organic food communities build their members' identities as consumers and environmentalists, both in physical and digital space, and the challenges they have faced, and how they overcome them. The current study used literature studies on individual motivation, identity, and community movement to answer the questions. The author also analysed how organic food communities build identities and empower organic food consumers, including unifying consumption and environmental preservation to face the challenges.

\section{Method}

To understand this issue, the author used qualitative research with narrative analysis by doing interviews, participatory observation, and document analysis. The author interviewed the founders of two communities. Firstly, Cristopher Emille Jayanata, the founder of Komunitas Organik Indonesia (KOI/ Indonesian Organic Community). The second was Wiji Suprayogi, the founder of Lingkar Organik (LO/ Organic Circle), a KOI member. They were chosen because of their knowledge of the communities' values and strategic activities, including how to treat their members and their reasoning. For the participatory observation, the author joined the WhatsApp Group of KOI members. The WhatsApp group is called Komunitas Selaras Alam (KSA/In Harmony with Nature Community) since 2018. The author also collected the community's documents, such as the profile of KOI and Balai Belajar Bali (Bali Learning Hall) as part of KOI. Besides the unpublished documents, the author also watched their websites and social media accounts to understand the communities' activities in digital public space, such as 
sharing the discussion events, products expo, and environmental campaign.

Visual data from the web page and social media accounts, documents text, the audio recordings, and the transcriptions were transformed into narratives classified into some codes that symbolized the contents characteristic. Then, those codes were classified into the themes related to this study, such as communities' profile and history, communities' structures, including values and norms, activities, challenges, and how they respond to the challenges. Then, the author analysed how their community maintains their members, from building the identities to production, distribution, and consumption of organic food.

\section{Results and Discussion}

The food contains value and symbols (Back et al., 2012). As a food, organic food also contains value and symbols. Moreover, as part of ethical eating, organic food is an instantiation of ethical eating that reflects the connection of individual commodities consumption and socio-environmental transformation (Johnston et al., 2011). Also, organic consumption is attached to diverse cultural ideas and contexts (Schösler et al., 2013). Therefore, producing and consuming organic food means producing and consuming the cultural value and symbol of organic food. Moreover, these cultural values and symbols can be attached as identities.

The attached identities are not only at the individual level but also community level. Moreover, the organic food producers, distributors, and consumers also tend to find the other person, community, and market to fulfil their need in organic food value, knowledge, and products. They will interact and build the communities that can sustain their interaction to fulfil their need for organic food.
Komunitas Organik Indonesia (KOI/ Indonesian Organic Community) is a community that provides and manages knowledge and product on organic commodities. KOI offers online and offline networking spaces for individuals interested in organic food. They have been using Komunitas Selaras Alam (KSA or In Harmony with Nature Community) WhatsApp groups to interact, socialize, and educate their members. KOI's members are not only at the individual but also the community level, such as Lingkar Organik (LO/ Organic Circle). Lingkar Organik (LO or Organic Circle) is a community that connects the farmers, sellers, and consumers of organic food In Yogyakarta and Central Java. Even though KOI is based in Jakarta and LO is based in Yogyakarta and Central Java, they have expanded their membership outside their physical location.

Both KOI and LO develop value, knowledge, and organic food materials in the multi-level organic food industrial cycle, from the producers and distributors to consumers. To understand how these communities, build multiple but seemingly contradictory identities, the author analysed various data in the results and discussions section, beginning from the community's profiles, how these communities build identities, to how they embed these multiple identities in community movement as green political consumerism, including how they face various challenges.

\section{Communities profile: The stories from their founders}

Today, the existence of Komunitas Organik Indonesia (KOI/Indonesian Organic Community) cannot be separated from their previous history. In 2008, this community was called Community of Indonesia's Quality \& Healthy Living (CIQHal) 2008, 


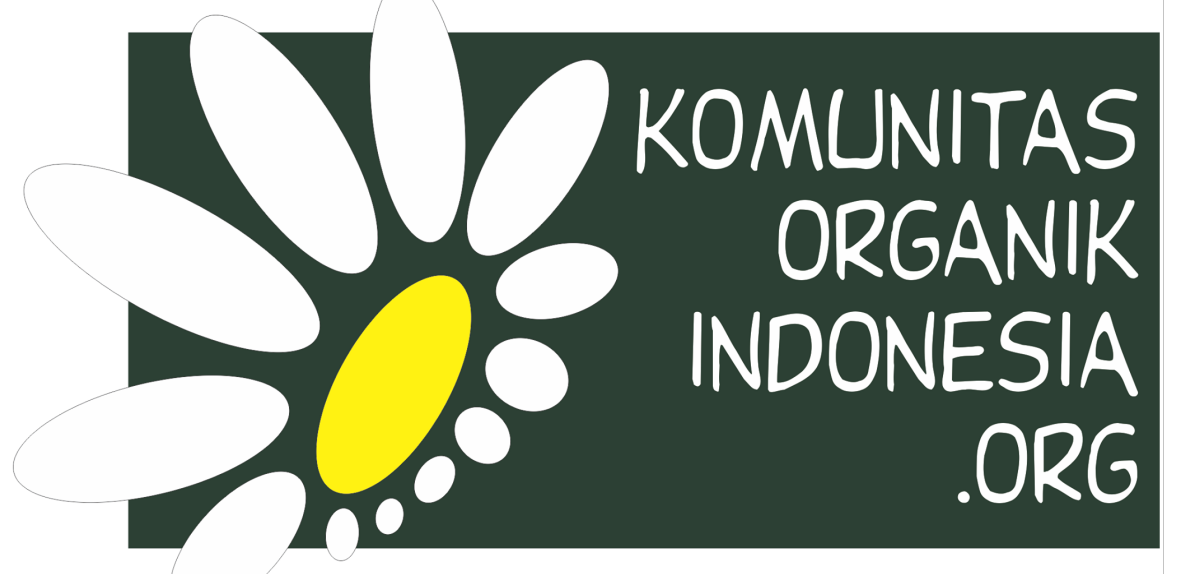

Figure 1. KOI's logo which contains the white flower as their symbol that they use to standardize the organic products and the community's website.

(Source: KOI's Facebook account, 2014)

which aimed to improve Indonesian people's life quality by providing good products (Komunitas Organik Indonesia, 2018). Then, in 2010, Masima-Prambors Group, a radio broadcasting station, helped establish KOI. They provided an online website for KOI and brought the organic industry in many sectors together.

The founder, Christopher Emille, or usually called Kang Emil, told the long stories of KOI during the interviews. The lack of organic food knowledge and a healthy and eco-friendly lifestyle in Indonesia have motivated KOI to provide education on organic food and environmental issues. Through Facebook, they attracted people who are interested in organic products. They also hold community gatherings every two weeks, where they discuss organic food and environmental issues like how to find a specific organic chicken, water, or organic rice. Every membercan share their knowledge and capability in the discussion. Besides organic food, they also promote other organic products, such as skincare and cosmetics. This community depends on not only the physical space but also digital space since the beginning. The authors observed how KOI develop their digital space based on the community's logo on their official website. In the past year, the website contains are integrated with their Instagram account.

Emille added that KOI also hold the Organic, Green, and Healthy Expo (OGHE) as a space for producers, distributors, and consumers to exchange organic food products. The first expo was planned in 2010 following the Ministry of Agricultural program called "Go Organic 2010". Unfortunately, the expo did not go well due to the lack of coordination with the Ministry officers. After that, KOI redesigned OGHE in 2011 and organized it without the government's assistance. KOI still organizes OGHE routinely every year. The community has chosen Jakarta as a place for OGHE I to OGHE IX. However, they organized OGHE Istimewa (Special OGHE) in Yogyakarta for once, in May 2015.

OGHE succeeded in attracting organic food producers, distributors, and consumers. Some even hold multiple roles simultaneously, such as the Lingkar Organik (LO or Organic Circle). LO shares organic food and organic farming knowledge to the farmers and the other communities. They discuss the organic farming requirements and how to market their products. They 


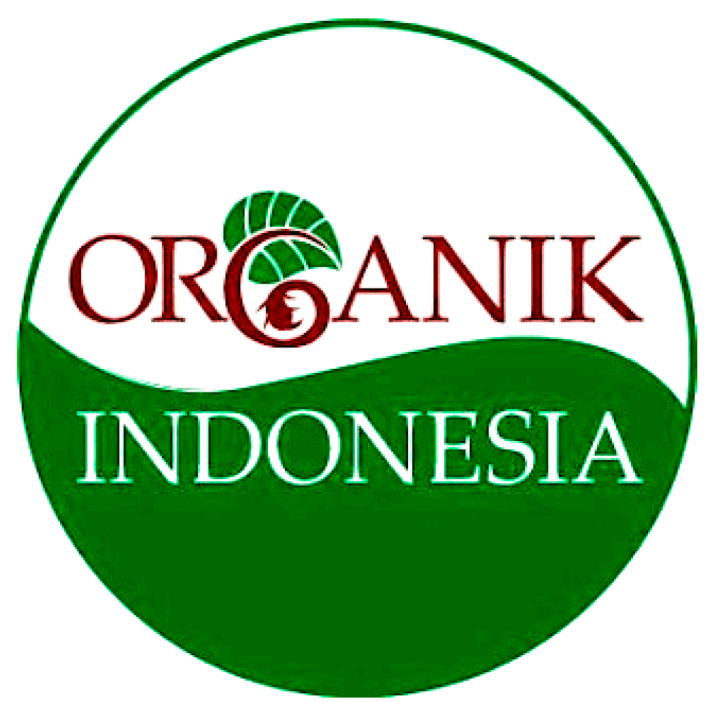

Figure 2. LO's logo which symbolized the community's value to achieve social-environmentally life balance.

(Source: lingkarorganik.or.id, n.d)

market the farmers' agricultural products and share the profit transparently.

Wiji Suprayogi, the founder of LO, told the stories behind LO's existence in the interview and online WhatsApp group sharing. LO started as a social movement to advocate for children who dropped out of schools. The parents of these children are primarily farmers in Yogyakarta and Central Java Provinces. Unfortunately, in the initial phase, they had funding issues. LO looked for ways to finance their movement that would still ensure independence and the values and capability of the community. After discussions with the children's families, LO decided to help fund the farmers' community by helping them to process and sell their agricultural products. However, the products must be environmentally friendly because LO wanted the children to live in a better environment. Nowadays, LO still helps students who drop out of school. They created and maintained the space to accommodate children's educational activities, which includes education to preserve the environment. Currently, LO already has more than 60 organic food products, including groceries, processed and ready-to-eat food. Most of the products are organic beans and nuts, rice, and tubers. The processed food is crackers, rengginang (traditional Indonesian rice crackers), flour, soy sauce, rice noodles, and others. LO has managed to balance the social and environmental life by developing organic food, which is also symbolized in their logo (see Figure 2).

Producing and marketing organic food is not easy because it needs to convey the value and the idea of a healthy and ecofriendly lifestyle. The communities need to share these values first with every involved member on how important a healthy and eco-friendly lifestyle is. Then, these communities share organic food-producing and processing methods. They also share real organic food with community members.

The community shares the values and concept of a healthy and eco-friendly lifestyle and organic food products by using diverse types of media. They use social media, like Facebook and Instagram, group instant messaging, like WhatsApp chat groups, community learning centres, and community gatherings as spaces for direct 


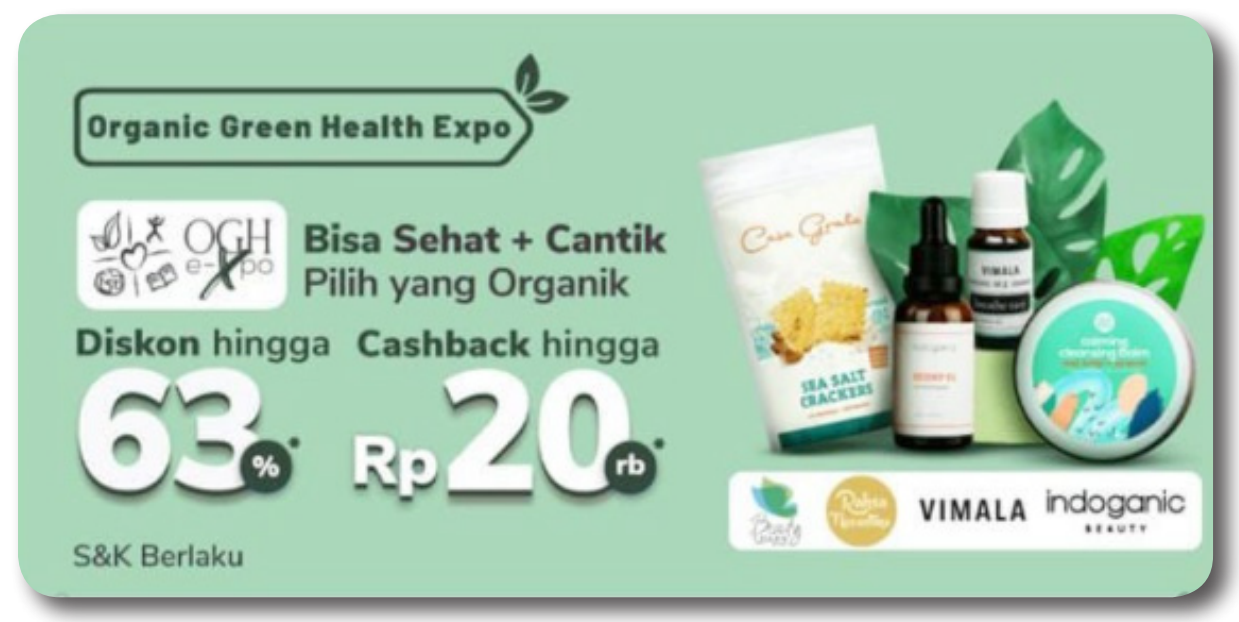

Figure 3. Header of OGHE X section in Tokopedia Source: KOI's Facebook Page (2020)

communication between the prospective customers and the sellers.

KOI's founder explained that KOI had created instant messaging groups called Komunitas Selaras Alam (KSA or Harmony with Nature Community), divided into eight WhatsApp chat groups. In those groups, they share values, healthy and eco-friendly lifestyles, and organic food products. They also organize group discussions on several issues with experts' speakers every two weeks. KOI also made Balai Belajar Bali (BBB or Bali Learning Hall) as a space to learn about living in harmony with nature in the agricultural area in Tabanan, Bali. BBB has provided organic farming and processed products such as red rice tea, Juruh (Balinese liquid palm sugar), and virgin coconut oil (Komunitas Organik Indonesia, 2019). Just like LO, they also share the values of healthy and eco-friendly lifestyles with farmers and children and persuade them to produce organic crops. Their sellers also spread the value when they sell the products to prospective customers, either face to face, through new media, or both.

To keep the communities in line with the value of a healthy lifestyle, they have structures to govern their members' behaviour. As Gatersleben et al. (2017) state, one of the factors that trigger green consumerism is the structural factor. Such a situation is also happening at the community level. For example, the products circulating in KOI and KSA WhatsApp Group must follow the standards to pass the Curation Board's verification and management approval. They then give a label to the product that passes the standards and gives it a chance to promote at one of their events.

The same process also happens even in the midst of the COVID-19 pandemic. The communities curated the product to join their annual event called Organic, Green, and Healthy Expo (OGHE) in Tokopedia, a digital marketplace (see Figure 3). Before the COVID-19 pandemic, the communities' events were held in Jakarta. However, due to the pandemic, they moved to digital space to reduce the potential contagiousness of COVID-19.

\section{How organic food community build their members' identities}

Identity is complex, from the characteristics of the identities themselves, how they emerge, and how they influence decision-making processes and behaviours. Dunn (2008:158) explains that identity is a 
common topic in the study of consumption, but it is usually oversimplified and has questionable claims. It often fails to examine the complexity and difficulties of identity and various forms and manifestations across the social spectrum. He adds that identity is never singular because it comprises perceptions, attitudes, values, beliefs, performances, selfunderstanding, and collective sensations.

Dunn (2008: 178-179) examines identities in the three dimensions. First, a personal identity refers to a person's unique personal configuration, whether physical, behavioural or personal. This embodiment of identity can be a part of a self-definition based on others' perception and judgment. Second, social identity refers to the social aspects of identity and other attributes. The dimension of social identity is divided into three bases. The first base is in the individual characteristic categorization, such as gender and race. The second base is based on social group membership. The third base somewhat overlaps with the institutionbased social role, like parents, students, or employees, or based on a group role such as chairman or follower. The last dimension is called cultural identity. It is often identified as a cultural tradition or heritage, as well as a part of ascribed status, such as ethnicity, race, nationality, religion, and family.

The multi-dimensions of identity are also attached in KOI and KOI's members. $\mathrm{KOI}$ as a community also has an identity that reflects the vision, orientation, and programs as their configuration and social attributes, which can be seen in their social media accounts and websites. The implementation of the vision, orientation, and programs also reflect their cultural tradition as a community. Then, the community's identity becomes part of their members' identity. If $\mathrm{KOI}^{\prime} \mathrm{s}$ identity is based on an organic-healthy and eco-friendly lifestyle, the members can also identify themselves with similar identities. Those identities are mutual; the members also build their internal identity and admit community identities to attach to them.

From the members' perspectives, there are several factors why they attach green identity as community members and consumers. Gatersleben et al. (2017) explain that the green consumer emergence factors are endogenous, exogenous, and structural. Endogenous factors describe internal motivation to perform green consumerism, such as values/attitudes, belief structures, and perception. Exogenous factors consist of social norms, peers, and influences. After that, choice architecture, decision nudges, and incentive structures are the structural factors that impact green consumerism performance (Sachdeva et al., 2015). Even though the consumers have the endogenous factor as motivation, it does not mean that they will choose to purchase green products. Purchasing green products is also affected by the price, quality, and shopping terms condition (Carrigan and Atalla, 2001 in Niinim, 2010). These are parts of exogenous and structural factors. Therefore, we need to understand these comprehensive factors to explain individual chosen identities as consumers and environmentalists by understanding organic foods.

To join and attach the identity, KOI members have an endogenous aspect. Mainly, their health and well-being condition are among their concern other than the environment. Their condition and concern motivate them to find or even build a community with the same vision. This situation happened to Wiji. As a member of $\mathrm{KOI}$, he is also a member of Lingkar Organik (LO/ Organic Circle), which makes LO becomes a part of the KOI community.

\footnotetext{
"(The first time) I found out about KOI from Mr. Emil (KOI Founder) himself. He came to Yogyakarta to meet others (organic communities). In the beginning, I was not interested in KOI. After all, we already have our internal networks.
} 
For organic produce-related activities, we need strong networks (in the internal community). Then, we saw the benefit of having networks with the other community. Also, we saw that Mr. Emil could disseminate local products to the wider market. I think we can depend on each other" (Interview with Wiji, 2019)

LO is concerned with the well-being of farmers and peasants' families, especially the children, as well as the environmental issue. His concern motivated him to build Lingkar Organik and join KOI to expand their networks.

To expand their networking, KOI also has worked together with other associations, such as Yayasan Anyo Indonesia (Indonesia Anyo Foundation) that helps children with cancer in Indonesia, Masyarakat Peduli Autis Indonesia (Indonesian Autistic Care Society), Autoimun Indonesia (Indonesian Autoimmune). KOI also worked with other organic food communities, such as Lingkar Organik, who also joined the Organic, Green, \& Healthy Expo (OGHE) held by KOI in the past.

"We just made an event involving artisans, producers, and organic farmers. They came, saw, and met with the consumers who were looking for [organic products]. If it is through conventional farmers or producers [without an expo], the organic food consumer would not necessarily be interested [to come]. If it is through us [OGHE], the organic food consumers already know [about us]." (Interview with Christopher Emille, 2019)

The similar political values in environmental issues, the potential to produce organic agricultural products, the economic needs, and the interest to develop organic food become the endogenous and exogenous factors that make the potential members and the community attracted to each other. For example, When Wiji or LO cooperates and becomes KOI's members, they have similar environmental responsibility, healthy lifestyle, and organic products. The endogenous factors that match the exogenous factors can make the community sustainable in implementing their vision. For example, the members build social identity voluntarily, such as their characteristic categorization as a 'green' person or 'green' community. Their social identity is also based on the community's membership and their role as community members. Thus, the community can emphasize their value to the community members. This is part of the exogenous factors that motivate the members to attach green identity and consume green products. Organic products also become the material symbol of the community and their member's culture.

Back et al. (2012) state that food is not just a physical and material object but also contains a definite symbolic meaning that reflects the consumer's value. Also, food selection is based on a cultural aspect rather than on a biological aspect. Miller et al. (2005) explain that artefacts are a part of a broader culture. When paired with the concept of commodities, aesthetics, and other things, artefacts will become a part of even broader world culture. In this case, organic foods as artefacts become a part of a broader culture called green consumerism in local and global development. A healthy and ecofriendly lifestyle is the symbol attached to organic food. These lifestyles are generally formed by political views and activism (Papaoikonomou, Cascon-Pereira, and Ryan, 2014). The political views on the environment and consumerism can encourage people to make organic food communities like KOI and LO. The encouragement also comes from the benefit of consuming organic food based on their experience. Moreover, as Autio \& Heinonen (2004) explain, by doing green consumerism, the consumer tends to feel altruistic, good, and life as warm light. Nevertheless, this encouragement will 
not be impacted if they do not have access to producing, marketing, and consuming organic products.

The community organization can solve those issues. KOI has programs for conditioning its members to organic food culture aside from shopping events and exhibitions. KOI also has organized culinary parties involving organic food sellers and other community members. For organic weekends, they ate processed organic foods. KOI also has an online discussion in KSA WhatsApp groups to influence and maintain their members' identities.

Similarly, LO has a program to discuss the organic agricultural process and product with the farmers, sellers, and consumers. The LO's sellers benefit from a healthy and eco-friendly lifestyle to the prospective consumers and how important it is to them. They offer not only organic food products but also the value and lifestyle that the consumers need. They have maintained the value and knowledge of organic food and its benefits. It is also the way they promote green products to their members. It is similar to de-Magistris \& Gracia (2015) study, which explains the Spain consumers' willingness to pay local and organic Almond is based on the promotion of sustainable consumption.

KOI and LO tend to have a dilemma in providing organic products. The producers and distributors aim to get a high profit, but there is a capacity limit on organic food production to preserve the environment. They cannot use the maximum amount of inorganic chemical booster to increase their agricultural products because it will harm the environment. Nevertheless, it does not necessarily mean they have a contradictory concept. These communities need to balance profits with environmental aspects, as done by the LO community.

Even though not every member follows the community values, in this case, when the members experience overlapping identities or identity conflict, a community member, LO chooses community values over personal values. Identity is an ideal image that keeps facing constant evaluation and reconstruction. When faced with behavioural choices, these communities choose the ideal behaviour that reflects their identity.

"The brown rice is harvested once every six months. Therefore, with the number of organic farmers (in the community), we have limited production. We already know the limit of agricultural products that we can produce. If there is more demand than supply, we are going to reject it. Other distributors maybe will try to meet the demand by taking products from other producers, but we are not the same because we cannot guarantee [the quantity and the quality of organic agricultural products].. we are not pursuing market quantity. We have learned that business is not merely about meeting the market needs..." (Interview with Wiji, 2019).

The identity conflict also occurs in organic food consumers. Consumption is identical to destruction. Even when one tries to save the environment, the act of consumption is destroying the environment. Therefore, green consumerism may be considered an oxymoron (Peattie, 2010). Nevertheless, it does not mean they contradict each other. The communities can still be an organic product consumer or even an organic product selfproducer, and also be an environmentalist. Gatersleben, Murtagh, Cherry, \& Watkins (2017) explain that identity can be plural where one action might be affected by multiple identities. Each identity will guide someone to behave in a specific context.

Organic food consumers in KOI have the freedom to consume and choose which identity they want to attach to themselves. They can identify themselves as an environmentally friendly person, healthy person, or person with an organic lifestyle. However, they are not as flexible as they 
seem. The communities have fundamental values that embody healthy and eco-friendly lifestyles. These values determine the acceptable behaviour within the community. If the members do not follow the standards, they will be shunned by the community. This situation has happened in KOI. Producers who did not follow KOI standards are not allowed to participate in OGHE. These standards are called white flower labels, which can be seen in their logo (see Figure 1). Besides the standardization for the producers, consumers in KSA WhatsApp chat groups who were not involved in the conversation and did not read the conversation in the online discussion at all gradually distanced themselves from the community. Those are their structural and natural selection in the internal communities.

The remaining active members are those who still identify themselves as organic food users. They are producers, distributors, consumers, or people who have multi-roles. This identity will be evaluated, verified, and recognized by other members of the community. The community has shaped its identity by providing organic food as groceries and processed food. Material objects and possessions can empower a subject's identity as part of material culture. In this case, organic food is part of a broader culture like green consumerism, which can be seen in healthy and environmentally friendly behaviours.

However, this identity does not guarantee that a person will always carry out a healthy and environmentally friendly lifestyle or purchase green products (Joshi \& Rahman, 2015). Even though Mohd Suki (2016) confirm that the elaboration of social, epistemic, and functional values, have social impacts on Malaysian consumer to purchase green products, but the value transformation into the act is not simple. Green product purchasing also depends on the ecology literation, emotional and social considerations, price, and financial aspects (Eze \& Ndubisi, 2013; Panjaitan \& Sutapa, 2010; Sangroya \& Nayak, 2017). In the broader context, like ethical eating, it needs to be facilitated by economic and cultural privileges (Johnston et al., 2011).

The community cannot ensure that every member will always behave according to their green consumer identity. Behaviour does reflect identity, but not all identities can be manifested in behaviour. The process of actualizing identity into concrete behaviour requires a process. Nevertheless, the power of green consumers cannot be undermined. Jain \& Kaur (2004) show that green consumer has explained that the existence of green cooperation and marketing-oriented have impacted by green consumerism. As Hussain \& Hussain (2015) state, consumers have the power to save the world.

\section{Actualizing multiple identities in behaviour and its challenges}

Multiple identities will always exist that can guide someone to behave in a specific context (Gatersleben et al., 2017). The identities are also symbolized in material that contains a cultural value that cannot always be actualized because it depends on the specific context. The notion of how material objects and possessions can empower and sharpen the identity of the subjects, their interactions, and their relationships with others is rooted in the material culture.

Materiality tends to be interpreted as an artefact, but Miller (2005) re-defines the meaning of materiality into a broader cultural conceptualization. Specific material processes can become parts of the world's culture (Miller, 1998). Based on that study, organic food is not only specific concrete material but also a value and symbol in a broader culture, such as green identity, consciousness for consumers, and a global green movement 
The broad cultural value of organic food is also reflected in the $\mathrm{KOI}$ and $\mathrm{LO}$ identities. To maintain the value, the communities internalize organic food symbols in their identities in processual, cultural, and structural, which can be seen in their interaction, rules, program, and vision. KOI has programs for conditioning the culture of organic food consumption on their members by sharing and developing organic food, as well as a healthy lifestyle. They start from the knowledge to the product access. It can be seen in their programs, such as an online discussion in KSA WhatsApp chat groups, seminars, and webinars to influence and maintain the identities of their members. KOI has made various grocery shopping events and exhibitions. They also have made culinary parties that invited organic food sellers and other community members to have an organic weekend by eating processed organic food.

LO shares knowledge and educates the farmers about how organic agricultural products can help their socio-environment life. They are not only producing organic agricultural products but also processing the agricultural products to be processed food and ready-to-eat food products with more than 60 organic food products sold to the market. Their products include organic beans and nuts, rice, tubers, and processed food like crackers, rengginang (rice crackers), flour, soy sauce, rice noodles, and other organic processed food. LO also must share knowledge on organic agricultural processes, products, and healthy eco-friendly lifestyle programs between the farmers, sellers, and consumers.

Both KOI and LO become spaces for individuals' private movement to access knowledge and organic food products. The individual's private movement can be transformed at the community level. Communities create offline spaces, such as gatherings, workshops, and expo. They also create online spaces, such as social media (Facebook and Instagram), instant messaging group chats (WhatsApp Messenger), and websites. Those spaces attract individuals who have endogenous factors to have a healthy lifestyle and care for the environment. At the same time, the community also builds exogenous and structural factors for the individual to have a healthy lifestyle and to care for the environment.

Nevertheless, having value, knowledge, and access to organic food products provided by communities does not guarantee that someone will consume organic food. Food prices, durability, taste, time of purchase, convenience will affect the behaviour of prospective consumers. Moisander (1991 in Niinimäki, 2010) states that price, quality, time, and comfort during the purchasing process will affect ethical consumption behaviour. Boström, M. \& Klintman (2017) found that most green consumers are white and come from upper-middle groups in the cultural capital, which often celebrate their green identity as good deeds. This situation is one of the challenges that communities must tackle if they want to expand the market for every class.

Besides providing organic food for every class in the market, the communities must compete with non-organic food products that tend to damage health and the environment. The distribution of these non-organic food products is massive, so they are more accessible to consumers. They also tend to be cheaper than organic food. Another challenge that hinders the consumption of organic food is the feedback from their environment. Taking the ideal identity or self-image into action will provoke responses from their surroundings. Some of these responses are quite unsupportive. Negative responses can come from groups that have conflicting or even similar identities.

The social group with similar identities is not always sharing their support with the 
other groups. This situation occurred during KOI's plan for the first OGHE in 2010 when they failed to collaborate with the Ministry of Agricultural. This failure led them to organize OGHE all by themselves for the following year. Social groups with opposite identities will also show opposition by developing non-organic products or attacking the organic food development process. LO has crossed paths with other social groups with different identities and political views on the agricultural environment. The opposing groups showed their disagreement and tried to sabotage LO through black campaigns. They banned people from joining the LO, and they destroyed the crops.

All the challenges can be categorized as internal and external factors that hinder the manifestation of values and identity's role of organic products and healthy and environmentally friendly lifestyles. Internal factors are the capability to provide organic food with accessible price, quality durability, and purchasing. External factors are responses from other groups, whether groups with similar ideas or groups with opposing identities. LO's experience of facing sabotage with a black campaign is part of the external hindrances. Therefore, the community needs to develop a strategy to face internal and external hindrances.

The community should develop better programs to nurture the value and approved behaviour continually to face internal and external hindrances. They need to overcome the problems that hinder them from producing, distributing, and consuming organic food products. The communities also need to improve the products selling in the digital market-based. Lin et al., (2020) explain that the characteristics of social commerce and organic food need to be in tandem, especially in the building functional and emotional value of organic food products. They can maintain interactivity, recommendation, and feedback, especially in e-commerce like Tokopedia, which different from the communities' social media account and expo in physical space.

\section{Conclusion}

Organic food communities such as Komunitas Organic Indonesia (KOI/ Indonesian Organic Community) and Lingkar Organic (LO/ Organic Circle) are spaces for sharing the organic food's cultural value and symbol. They attract people who have endogenous factors to have a healthy lifestyle and to care for the environment by producing and consuming organic food. Communities also become the exogenous and structural factors in building the identities by sharing value, knowledge, and organic food products with various programs.

Identity empowerment does not guarantee that someone will actualize it in an act. Therefore, the communities play an important role in helping them by sharing detailed knowledge on implementing a healthy and environmentally friendly lifestyle. They will also provide easy access for their members to obtain organic food products by exchanging verified information curated by community managers. They provide various purchasing methods to facilitate prospective consumers either through online groups or a live expo. This is part of the communities' internal challenge to influence the value to the member.

The communities also face external challenges that hinder them from achieving the communities' goals both from the person or social groups with similar values and different values. Therefore, the community needs to develop a strategy to face the internal and external hindrances that not only relate to the issues but also the spaces where the issues happen and can be solved.

Both KOI and LO use physical and digital spaces to share value, knowledge, and organic products. In their developments, 
they also transform their activities, like expo, into the digital marketplace. Nevertheless, the characteristic of this digital space for the expo is different from physical space and the other digital spaces like WhatsApp group, Facebook, and Instagram. In the digital marketplace like Tokopedia, they need more to maintain interactivity, recommendation, and feedback, which is usually easier to do in physical space or social media. Therefore, the community needs to understand the characteristic of every kind of new media or digital space to maintain the communities' value and to provide organic products as part of communities' development. This condition is also needed to be developed for future research.

\section{Declaration of Ownership}

This article is my original work.

\section{Acknowledgments}

I would like to thank the communities, Komunitas Organik Indonesia and Lingkar Organik Indonesia, for their kindness and helpful information. I also want to thank to the acquitances, Prof. Dr. Sudarsono Hardjosoekarto, Francisia SSE Seda, Ph.D., Andi Rahman Alamsyah, M.Si., Raphaella Dewantari Dwianto, Ph.D., for their reviews on this earlier manuscript.

\section{Conflict of Interest}

There is no conflict of interest to declare in this article.

\section{Ethical Clearance}

This study was approved by the institution.

\section{References}

Akenji,L.(2014).Consumer scapegoatismand limits to green consumerism. Journal of Cleaner Production, 63, 13-23. h t t p s : // doi.org/10.1016/j.jclepro.2013.05.022

Atmadi, G. (2013). The utilities of new media for organic community of Indonesia. The Asian Conference on Media and Mass Communication 2013, 397-407. http:// papers.iafor.org/wp-content/uploads/ conference-proceedings/MediAsia/ MediAsia2013_proceedings.pdf

Autio, M., \& Heinonen, V. (2004). To consume or not to consume? Young, 12(2), 137-153. https://doi. org/10.1177/1103308804042104

Back, L., Bennett, A., Edles, L. D., Gibson, M., \& Inglis, D. (2012). Cultural sociology: An introduction. Wiley-Blackwell.

Boström, M., \& Klintman, M. (2017). Can we rely on 'climate-friendly' consumption? Journal of Consumer Culture, 19(3), 359-378. https://doi. org $/ 10.1177 / 1469540517717782$

Buttel, F. H. (2003). Environmental sociology and the explanation of environmental reform. Organization $\mathcal{E}$ Environment, 16(3), 306-344. https://doi. org/10.1177/1086026603256279

de-Magistris, T., \& Gracia, A. (2015). Consumers' willingness-to-pay for sustainable food products: The case of organically and locally grown almonds in Spain. Journal of Cleaner Production, 118, 97-104. https://doi.org/10.1016/j. jclepro.2016.01.050

Dunn, R. G. (2008). Identifying consumption: Subjects and objects in consumer society. Temple University Press.

Eze, U. C., \& Ndubisi, N. O. (2013). Green buyer behavior: Evidence from Asia consumers. Journal of Asian and African Studies, 48(4), 413-426. https://doi. org/10.1177/0021909613493602 
Gatersleben, B., Murtagh, N., Cherry, M., \& Watkins, M. (2017). Moral, wasteful, frugal, or thrifty? Identifying consumer identities to understand and manage proenvironmental behavior. Environment and Behavior, 51(1), 24-49. https://doi. org/10.1177/0013916517733782

Hardner, J., \& Rice, R. (2002). Rethinking green consumerism. Scientific American, 286(3), 88-95. https://doi.org/10.1038/ scientificamerican0502-88

Harrison, B. (2006). Shopping to save: Green consumerism and the struggle for northern Maine. Cultural Geographies, 13(3), 395-420. https://doi. org/10.1191/1474474006eu365oa

Hussain, J. S., \& Hussain, J. (2015). A conceptual framework on the power of consumers in pushing corporate social responsibility towards sustainable development. Indian Journal of Corporate Governance, 8(1), 68-83. https://doi. org/10.1177/0974686215574432

Jain, S. K., \& Kaur, G. (2004). Green marketing: An attitudinal and behavioural analysis of Indian consumers. Global Business Review, 5(2), 187-205. https://doi. org/10.1177/097215090400500203

Johnston, J., Szabo, M., \& Rodney, A. (2011). Good food, good people: Understanding the cultural repertoire of ethical eating. Journal of Consumer Culture, 11(3), 293-318. https://doi. org/10.1177/1469540511417996

Joshi, Y., \& Rahman, Z. (2015). Factors affecting green purchase behaviour and future research directions. International Strategic Management Review, 3(1-2), 128-143. https://doi.org/10.1016/j. ism.2015.04.001

Komunitas Organik Indonesia. (2018). Community profile: Komunitas Organik Indonesia. Unpublished.

Komunitas Organik Indonesia. (2019). About Balai Belajar Bali. Unpublished.
Lin, J., Guo, J., Turel, O., \& Liu, S. (2020). Purchasing organic food with social commerce: An integrated foodtechnology consumption values perspective. International Journal of Information Management, 51. https://doi. org/10.1016/j.ijinfomgt.2019.11.001

Ma, A. J., Zhao, H. Z., \& Ren, F. Z. (2010). Study on food life cycle carbon emissions assessment. Procedia Environmental Sciences, 2, 1983-1987. https://doi. org/10.1016/j.proenv.2010.10.213

Miller, D. (1998). Material cultures: Why some things matter. In Material cultures: Why some things matter. https:/doi. org/10.1525/aa.1999.101.2.458

Miller, D. (2005). Materiality: An introduction. In D. Miller (Ed.), Materiality. Duke University Press.

Mohd Suki, N. (2016). Consumer environmental concern and green product purchase in Malaysia: Structural effects of consumption values. Journal of Cleaner Production, 132, 204-214. https:// doi.org/10.1016/j.jclepro.2015.09.087

Montanari, M. (2017). Food is culture. Columbia University Press. http://www. elsevier.com/locate/scp

Monteith, W., \& Giesbert, L. (2016). 'When the stomach is full we look for respect': Perceptions of 'good work' in the urban informal sectors of three developing countries. Work, Employment and Society, 31(5), 816-833. https://doi. org/10.1177/0950017016650606

Niinimäki, K. (2010), Eco-clothing, consumer identity and ideology. Sust. Dev., 18(3),150-162. https://doi.org/10.1002/ sd. 455

Panjaitan, T. W. S., \& Sutapa, I. N. (2010). Analysis of green product knowledge, green behavior and green consumers of Indonesian students (case study for universities in Surabaya). 2010 IEEE International Conference on Industrial 
Engineering and Engineering Management, Macao, China, 2268-2272. https://doi. org/10.1109/IEEM.2010.5674276

Papaoikonomou, E., Cascon-Pereira, R., \& Ryan, G. (2014). Constructing and communicating an ethical consumer identity: A social identity approach. Journal of Consumer Culture, 1-23. https:// doi.org/10.1177/1469540514521080

Peattie, K. (2010). Green consumption: Behavior and norms. Annual Review of Environment and Resources. https://doi.org/10.1146/annurevenviron-032609-094328

Sachdeva, S., Jordan, J., \& Mazar, N. (2015). Green consumerism: Moral motivations to a sustainable future. Current Opinion in Psychology, 6, 60-65. https://doi. org/10.1016/j.copsyc.2015.03.029
Sangroya, D., \& Nayak, J. K. (2017). Factors influencing buying behaviour of green energy consumer. Journal of Cleaner Production, 151, 393-405. https://doi. org/10.1016/j.jclepro.2017.03.010

Schösler, H., de Boer, J., \& Boersema, J. J. (2013). The organic food philosophy: A qualitative exploration of the practices, values, and beliefs of Dutch organic consumers within a cultural-historical frame. Journal of Agricultural and Environmental Ethics, 26(2), 439-460. https://doi.org/10.1007/s10806-012-93920

Tan, L. P., Johnstone, M. L., \& Yang, L. (2016). Barriers to green consumption behaviours: The roles of consumers' green perceptions. Australasian Marketing Journal, 24(4), 288-299. https://doi. org/10.1016/j.ausmj.2016.08.001 